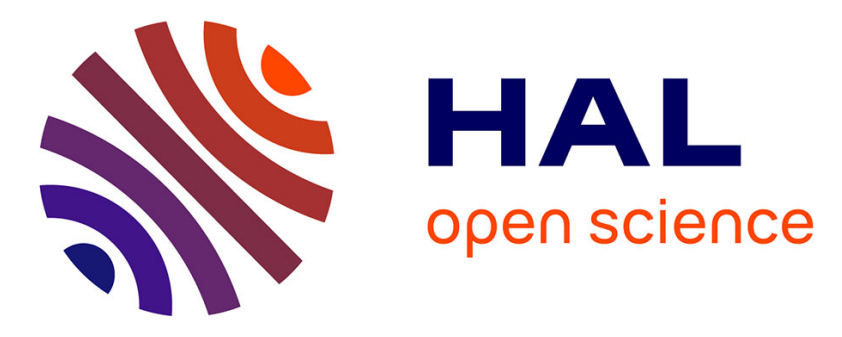

\title{
The association of chronic health status and survival following ventricular fibrillation cardiac arrest: Investigation of a primary myocardial mechanism
}

Florence Dumas, Jason Coult, Jennifer Blackwood, Peter Kudenchuk, Alain Cariou, Thomas D. Rea

\section{To cite this version:}

Florence Dumas, Jason Coult, Jennifer Blackwood, Peter Kudenchuk, Alain Cariou, et al.. The association of chronic health status and survival following ventricular fibrillation cardiac arrest: Investigation of a primary myocardial mechanism. Resuscitation, 2019, 137, pp.190 - 196. 10.1016/j.resuscitation.2019.02.018 . hal-03486886

\section{HAL Id: hal-03486886 https://hal.science/hal-03486886}

Submitted on 20 Dec 2021

HAL is a multi-disciplinary open access archive for the deposit and dissemination of scientific research documents, whether they are published or not. The documents may come from teaching and research institutions in France or abroad, or from public or private research centers.
L'archive ouverte pluridisciplinaire HAL, est destinée au dépôt et à la diffusion de documents scientifiques de niveau recherche, publiés ou non, émanant des établissements d'enseignement et de recherche français ou étrangers, des laboratoires publics ou privés.

\section{(c)(1) $\$$}

Distributed under a Creative Commons Attribution - NonCommercial| 4.0 International 


\section{The association of chronic health status and survival following ventricular 2 fibrillation cardiac arrest: Investigation of a primary myocardial mechanism.}

3

4 Florence Dumas ${ }^{1,2}$, Jason Coult ${ }^{3,4}$, Jennifer Blackwood ${ }^{5}$, Peter Kudenchuk ${ }^{5,6}$, Alain 5 Cariou ${ }^{1}$, Thomas D Rea ${ }^{5,6}$

$11{ }^{1}$ Inserm U970, Parisian Cardiovascular Research Center, Paris Descartes University, Paris, 12 France

$13{ }^{2}$ Emergency Department, Cochin/Hotel-Dieu Hospital, APHP, Paris, France

$14{ }^{3}$ Center for Progress in Resuscitation, University of Washington, Seattle, WA, United States;

$15{ }^{4}$ Department of Bioengineering, University of Washington, Seattle, WA, United States.

$16{ }^{5}$ Emergency Medical Services, Division of Public Health for Seattle and King County,

$17 \quad{ }^{6}$ University of Washington, Seattle, WA, USA

23 Word Count : 3439

24 Abstract : 214 words

25 Figures+ Tables : $1+4$

26 References :29

27

28 Corresponding author: 
Abstract

Introduction: Quantitative waveform measures are a surrogate of the acute physiological

status of the myocardium and predict survival following ventricular fibrillation out-ofhospital cardiac arrest (OHCA). We investigated whether the amplitude spectrum area (AMSA) waveform measure mediates the adverse relationship between increasing burden of chronic health conditions and lower likelihood of survival.

Methods: We performed a cohort investigation of persons $>=18$ years who suffered ventricular fibrillation OHCA between 2008-2015 in a metropolitan emergency medical service (EMS) system. The count of chronic health conditions was determined using the Charlson Comorbidity Index (CCI). AMSA was calculated just prior to the initial shock. We used multivariable logistic regression to assess the relationship between CCI and survival-todischarge in models first without and then with AMSA to determine the extent to which AMSA attenuated the CCI-survival association.

Results: Of the 716 eligible patients, 422/716 (59\%) had at least one chronic health condition; $21.8 \%$ with one, $19.6 \%$ with two, $10.3 \%$ with 3 , and $7.3 \%$ with $\geq 4$. Survival-to-discharge was $45 \%$ (324/716). In the multivariable model adjusted for traditional Utstein characteristics, increasing CCI was associated with lower odds of survival (Odds ratio (OR) (95\% confidence interval $]=0.82[0.72,0.93]$ for each additional chronic health condition).

50 The addition of AMSA to the model only modestly attenuated the CCI-survival association $(\mathrm{OR}=0.85[0.74,0.98])$

53 Conclusion: The waveform measure AMSA - a surrogate for the physiological status of the 54 myocardium - mediated only a modest portion of the association between increasing burden 
55 of chronic health conditions and lower likelihood of survival following ventricular fibrillation 56 OHCA.

57 
Out-of-hospital cardiac arrest (OHCA) is a leading cause of mortality worldwide ${ }^{1}$.

61 Considerable programmatic and research efforts are directed toward improving resuscitation.

62 A key to improving outcomes is to understand the factors that influence resuscitation. The

63 Utstein data elements, which include demographic, circumstance, and resuscitation care

64 characteristics predict outcome but collectively only account for a modest portion of outcome variability $^{23}$.

66

67 Increasing evidence has indicated that the burden of chronic health conditions can adversely

68 influence prognosis ${ }^{4-6}$. The reasons for this association are not well-understood. One

69 hypothesis is that chronic health conditions directly affect the myocardial substrate, making

70 patients with excess chronic health conditions less responsive to treatment and hence less

71 likely to survive following ventricular fibrillation (VF) OHCA. There is however a lack of

72 rigorous investigation evaluating the relationship between chronic health conditions and the

73 heart's physiologic status during VF OHCA ${ }^{7-10}$. Identifying the mechanism(s) by which

74 chronic health conditions influence prognosis can improve scientific understanding of

75 resuscitation, help explain outcome differences across populations or geographies, and

76 potentially provide the basis to improve care.

77

78 Quantitative measures of the VF waveform are dynamic and predict outcome over the course

79 of resuscitation ${ }^{11-14}$. These measures can correspond to the heart's ischemic burden and provide an assessment of energy status of the myocardial substrate ${ }^{15} 16$. Thus, as a surrogate for myocardial status, quantitative waveform measures provide a means to evaluate whether

82 chronic health conditions might confer excess risk through a primary myocardial mechanism.

83 We used the waveform measure amplitude spectrum area (AMSA) as it predicts both shock- 
specific ECG outcome (return of organized rhythm) and clinical outcome (return of circulation and survival to hospital discharge) across different human VF populations ${ }^{11-14}$. To test this theory, we hypothesized that waveform measures account for the adverse association between increasing burden of chronic health conditions and outcome following VF OHCA.

\section{Methods}

Design, study population, and setting:

We performed a cohort investigation of persons 18 years or older who suffered non-traumatic OHCA and presented with ventricular fibrillation between January 1, 2008 and December 31, 2015 in a large metropolitan emergency medical service (EMS) system. Because the investigation required ECG information prior to the initial shock from the defibrillator recording, we a-priori excluded cases that received a shock from a non-EMS defibrillator i.e. public access defibrillator or law enforcement - as these would not routinely be available for review and analysis. We also excluded cases where the EMS provided the initial shock but the EMS defibrillator download was unavailable or technically not adequate (corrupted or missing ECG).

The EMS system serves a population of approximately 1.3 million persons residing in urban, suburban, and rural settings covering an area of about 2000 square miles. The EMS is a twotiered system. The first tier is emergency medical technician-trained firefighters who provide basic life support and are equipped with automated external defibrillators. The second tier is paramedics trained in advanced life support including manual rhythm interpretation and defibrillation, intubation, and intravenous medication therapies. Resuscitation care is based on the American Heart Association guidelines ${ }^{17}$. Patients who are resuscitated are transported to area hospitals, each equipped with coronary catheterization and intensive care 
109 services. Hospital-based care is at the discretion of the treating physician ${ }^{18}$. The

110 institutional review boards at the University of Washington and Public Health - Seattle \&

111 King County approved the study.

113 Data collection and definitions:

114 The EMS system maintains an ongoing registry of all EMS-treated cardiac arrests.

115 Information about demographics, circumstances, care, and outcome is ascertained using

116 emergency dispatch, EMS, defibrillator, hospital and death records. The information is

117 organized according to the Utstein Guidelines for reporting OHCA ${ }^{3}$. Investigators abstract

118 information from dispatch and EMS records blinded to outcome status.

120 Information about pre-existing, clinically-recognized chronic health conditions was collected

121 from the EMS reports ${ }^{19}$. Information from EMS records is available for all treated patients

122 and has a fair to good kappa with hospital-based information. Inter-reviewer reliability for

123 selected conditions has revealed a high level of agreement. The complete abstraction form

124 including health conditions and chronic medication treatments has been previously published

$125{ }^{6}$. Chronic conditions were tallied to generate the Charlson Comorbidity Index (CCI) and

126 categorized into 5 groups $(0,1,2,3$ or $\geq 4)$ with higher numbers indicating greater burden of

127 chronic health conditions ${ }^{20}$. The primary outcome was survival, as confirmed by vital status

128 at hospital discharge.

$130 E C G$

131 Real-time ECG tracings were collected from the EMS defibrillator recording. ECGs were

132 collected from MRx and ForeRunner 3 (Philips Healthcare, Bothell, WA) defibrillators and

133 from Lifepak 12 and Lifepak 15 (Physio-Control, Redmond, WA) defibrillators. MRx ECGs 
134 were analyzed at their original sample rate of $250 \mathrm{~Hz}$, ForeRunner 3 ECGs were resampled

135 from $200 \mathrm{~Hz}$ to $250 \mathrm{~Hz}$, and Lifepak ECGs were resampled from $125 \mathrm{~Hz}$ to $250 \mathrm{~Hz}$. All ECG

136 segments were bandpass-filtered from $4-48 \mathrm{~Hz}$ using a $4^{\text {th }}$-order Butterworth filter with a

137 zero-phase implementation

138

139 AMSA Calculation

140 We extracted a 5-second VF ECG epoch from each patient during the CPR pause

141 immediately before the first shock. Pauses in CPR were confirmed by review of the chest

142 impedance signal. We used these 5-second ECG epochs to generate the amplitude spectrum

143 area (AMSA), a frequency-domain quantitative waveform measure. AMSA was calculated as

$144 A M S A=\sum_{m=4 H z \cdot N / f_{s}}^{48 H z \cdot N / f_{s}}\left(X_{m} f_{m}\right)$, where $X_{m}$ are the one-sided Discrete Fourier Transform

145 magnitudes calculated from a Hanning-windowed VF ECG segment of $N$ samples, $f_{m}$ are the

146 frequency values (in $\mathrm{Hz}$ ) corresponding to each $X_{m}$ magnitude, and $f_{s}$ is the sampling rate. ${ }^{16}$

$147^{21-23}$ As AMSA is calculated using the sum of the products of each frequency value and its

148 corresponding magnitude, a VF ECG segment with more high-frequency content will

149 typically have a higher AMSA value. Data extraction and processing were performed using

150 MATLAB R2017a (The Mathworks Inc, Natick, MA). ${ }^{24} 25$

151

152

153 Statistical analysis:

154 We used descriptive statistics to summarize categorical variables as proportions, and

155 continuous variables as mean with standard deviation for normal distribution or as median

156 with interquartile range for non-normal distribution. We conducted analyses to understand

157 whether the association between chronic health conditions and survival was mediated by the

158 AMSA waveform measure. We used logistic regression to determine the unadjusted 
159 association between Utstein parameters, chronic health conditions, and AMSA and outcome.

160 We constructed a multivariable model that included the Utstein predictors and the CCI with

161 CCI being modeled as a continuous categorical variable. We then added AMSA quartile

162 modeled as a continuous categorical variable to the multivariable model. Given the

163 hypothesis that chronic conditions affect prognosis through a cardiac mechanism, we

164 expected that addition of AMSA to the model would attenuate the association between

165 chronic health conditions and outcome. We measured this contribution on a percentage basis

166 using the equation: 1- (beta chronic health conditions adjusted/beta chronic health conditions baseline), where

167 beta are the multivariable logistic model coefficients. ${ }^{28}$

168

169 Finally, we assessed for differences in the association between chronic health conditions,

170 AMSA, and outcome among subgroups defined by witness status, age $(>=65$ versus $<65$

171 years), and sex by including an interaction (cross-product) term between chronic health

172 condition group and the covariates of interest. All tests were performed using STATA/SE

17314.2 (Lakeway Drive, TX, USA). A p-value < 0.05 was considered statistically significant. 


\section{Results}

During the study period, 1611 persons had OHCA with an initial rhythm of VF. Of

176

177

178

179

180

181

182

183

184

185

186

187

188

189

190

191

192

193

194

195 Table 4 presents the results of the logistic regression models. In unadjusted models,

196

$197=0.79[\mathrm{CI}=0.70-0.89], \mathrm{p}<0.001)$, while increasing quartile of AMSA was associated with an

198 increasing likelihood of survival (trend OR $=1.31[1.24-1.37], \mathrm{p}<0.001$ ). In the 
199 multivariable model that adjusted for Utstein predictors, increasing CCI remained associated 200 with a lower likelihood of survival (trend $\mathrm{OR}=0.82(0.72-0.93], \mathrm{p}=0.003)$. When AMSA 201 quartile was added to the multivariable model, the association between CCI and survival was 202 attenuated only slightly (trend OR $=0.85[0.74-0.98]$ ). The beta for chronic health conditions 203 was -0.202 without AMSA and -0.163 with AMSA in the multivariable model, indicating 204 AMSA mediates 19\% (1- [beta 2/beta 1]) X 100) of the association between chronic health 205 conditions and survival.

206

207 In sensitivity analyses, we did not observe an interaction between chronic health conditions 208 and survival according to subgroup characteristics that had an apparent association with 209 survival outcome (Table 4), including witnessed arrest status ( $\mathrm{p}$ for interaction=0.69), age (p 210 for interaction $=0.41$ ), or sex ( $\mathrm{p}$ for interaction $=0.43)$. 


\section{Discussion}

213 In the present cohort investigation of OHCA due to VF, an increasing burden of chronic

214 health conditions was associated with a lower likelihood of survival after adjustment for

215 traditional Utstein elements describing demographic, circumstance, and response

216 characteristics. When the model also incorporated AMSA, the adverse association of chronic

217 health conditions was attenuated only modestly and retained its independent association with

218 survival. Collectively, the results suggest that myocardial substrate as measured by the

219 AMSA waveform measure does not primarily mediate the association between an increasing

220 burden of chronic health conditions and lower likelihood of survival following VF arrest,

221 suggesting that other alternative mechanisms should be considered.

223 Prior research has demonstrated that the Utstein elements are important predictors but are not

224 sufficient to explain outcome differences within or across systems, and collectively account

225 for only a modest proportion of the variability in survival ${ }^{22}$. The results of current and prior

226 investigations indicate that incorporating chronic health conditions can improve prediction.

227 In the present study, an increasing burden of chronic health conditions was associated with a

228 reduced likelihood of survival in a dose-dependent fashion. The question then is what

229 mechanisms might mediate this adverse risk given that all patients in the current cohort

230 presented with VF ventricular fibrillation in a model that was adjusted for Utstein

231 characteristics?

233 In this study, we investigated whether a primary myocardial mechanism might explain the

234 association between comorbidity and OHCA outcome. We hypothesized that chronic health

235 conditions might affect the intrinsic myocardial expression of VF. Specifically, we used the

236 AMSA quantitative waveform measure derived from the ECG captured just prior to the initial 
237 shock. Previous research suggests that waveform measures such as AMSA might serve as a surrogate for coronary perfusion pressure and myocardial energy during resuscitation ${ }^{78}$. Indeed we observed a strong and independent relationship between increasing AMSA and a greater likelihood of survival. However, inclusion of AMSA in the multivariable model

241 accounted for only a modest proportion of the adverse relationship between chronic health 242 conditions and outcome, suggesting that other mechanisms account for the association.

244 Other mechanisms might include variability in pre-hospital emergency medical services 245 (EMS) interventions, which could differ according to chronic health status. Although the 246 Utstein elements include categorical EMS measures, there may be differences in quantitative 247 aspects of care such as the timing and quality of bystander and EMS CPR. Alternatively, hospital care may differ according to the burden of chronic health conditions, and could influence the types and extent of hospital intervention and support.

251 The current study has limitations. Specifically we were not able to evaluate more detailed 252 potential mediators to include the aforementioned quantitative prehospital measures of resuscitation or in-hospital care. We used a clinical outcome (survival) that is several steps

254 removed from the initial waveform measure. The use of more proximal outcome could 255 reveal different relationships among CCI, AMSA, and intermediate outcomes such as 256 organized rhythm following the shock. The study used an observational design. Thus 257 caution must be exercised in attributing cause-and-effect outcome relationships as it relates to 258 chronic health conditions and AMSA, though these findings were adjusted for potential 259 confounders. Chronic health conditions in this study were ascertained by EMS providers. 260 Although this approach may underestimate the prevalence of comorbidity, it captures this 261 information in all patients, including those who did not survive to hospital admission and 
262 whose comorbidities might not otherwise be known. Moreover the accuracy of this methodology has been validated when compared with hospital-sourced information. ${ }^{19}$ The current study evaluates cumulative comorbidity as measured by the Charlson Index and does not investigate a specific comorbidity, its influence on outcome, or whether this relationship may be mediated by primary cardiac mechanism as measured by the AMSA waveform.

267 Indeed specific comorbidities may have distinct mechanisms influencing outcome. We used 268 AMSA as a surrogate of myocardial status given this waveform measure is well-tested as a predictor of outcome. Other waveform measures, or alternative surrogates for myocardial status, may have produced different results. Finally, the results come from a mature metropolitan EMS system that achieves a relatively high survival such that the results may

272 not be generalizable to all communities. These limitations should be balanced with the investigation's strengths; a well-characterized cohort of persons with VF arrest that incorporated quantitative waveform measures to evaluate novel relationships potentially responsible for resuscitation mechanisms.

\section{Conclusions}

278 An increasing burden of chronic health conditions was associated with a lower likelihood of survival following VF OHCA independent of traditional Utstein predictors. The quantitative waveform measure AMSA - a surrogate for the physiological status of the myocardium -

281 accounted for only a modest portion of the association between chronic health conditions and 282 outcome, suggesting other mechanisms are likely responsible for this association. Future study should investigate alternative mechanisms to account for this association as a means to understand heterogeneity of outcome and potentially help improve resuscitation care.

\section{Acknowledgements}


287 We appreciate the efforts of King County EMS personnel, who persistently strive to improve 288 resuscitation care. This project was supported in part by a grant from the Laerdal Foundation 289 and the National Institute for Biomedical Imaging and Bioengineering of the National 290 Institutes of Health (T32EB001650). The content of this work is the responsibility of the 291 authors and does not represent the views of Public Health - Seattle \& King County or of any 292 funding organizations.

293 
295

296

297

298

299

300

301

302

303

304

305

306

307

308

309

310

311

312

313

314

315

316

317

318

319

320

321

322

323

324

325

326

327

328

329

330

331

332

333

334

335

336

337

338

339

1. Benjamin EJ, Virani SS, Callaway CW, Chamberlain AM, Chang AR, Cheng S, et al. Heart Disease and Stroke Statistics-2018 Update: A Report From the American Heart Association. Circulation 2018;137(12):e67-e492.

2. Rea TD, Cook AJ, Stiell IG, Powell J, Bigham B, Callaway CW, et al. Predicting survival after out-of-hospital cardiac arrest: role of the Utstein data elements. Annals of emergency medicine 2010;55(3):249-57.

3. Perkins GD, Jacobs IG, Nadkarni VM, Berg RA, Bhanji F, Biarent D, et al. Cardiac arrest and cardiopulmonary resuscitation outcome reports: update of the Utstein Resuscitation Registry Templates for Out-of-Hospital Cardiac Arrest: a statement for healthcare professionals from a task force of the International Liaison Committee on Resuscitation (American Heart Association, European Resuscitation Council, Australian and New Zealand Council on Resuscitation, Heart and Stroke Foundation of Canada, InterAmerican Heart Foundation, Resuscitation Council of Southern Africa, Resuscitation Council of Asia); and the American Heart Association Emergency Cardiovascular Care Committee and the Council on Cardiopulmonary, Critical Care, Perioperative and Resuscitation. Circulation 2015;132(13):1286-300.

4. Hallstrom AP, Cobb LA, Yu BH. Influence of comorbidity on the outcome of patients treated for out-of-hospital ventricular fibrillation. Circulation 1996;93(11):201922.

5. Carew HT, Zhang W, Rea TD. Chronic health conditions and survival after out-ofhospital ventricular fibrillation cardiac arrest. Heart 2007;93(6):728-31.

6. Dumas F, Blackwood J, White L, Fahrenbruch C, Jouven X, Cariou A, et al. The relationship between chronic health conditions and outcome following out-ofhospital ventricular fibrillation cardiac arrest. Resuscitation 2017;120:71-76.

7. Neumar RW, Brown CG, Van Ligten P, Hoekstra J, Altschuld RA, Baker P. Estimation of myocardial ischemic injury during ventricular fibrillation with total circulatory arrest using high-energy phosphates and lactate as metabolic markers. Annals of emergency medicine 1991;20(3):222-9.

8. Salcido DD, Menegazzi JJ, Suffoletto BP, Logue ES, Sherman LD. Association of intramyocardial high energy phosphate concentrations with quantitative measures of the ventricular fibrillation electrocardiogram waveform. Resuscitation 2009;80(8):946-50.

9. Hall M, Phelps R, Fahrenbruch C, Sherman L, Blackwood J, Rea TD. Myocardial substrate in secondary ventricular fibrillation: insights from quantitative waveform measures. Prehospital emergency care : official journal of the National Association of EMS Physicians and the National Association of State EMS Directors 2011;15(3):388-92.

10. Hulleman M, Salcido DD, Menegazzi JJ, Souverein PC, Tan HL, Blom MT, et al. Predictive value of amplitude spectrum area of ventricular fibrillation waveform in patients with acute or previous myocardial infarction in out-of-hospital cardiac arrest. Resuscitation 2017;120:125-131.

11. Ristagno G, Mauri T, Cesana G, Li Y, Finzi A, Fumagalli F, et al. Amplitude spectrum area to guide defibrillation: a validation on 1617 patients with ventricular fibrillation. Circulation 2015;131(5):478-87. 
12. Coult J, Sherman L, Kwok H, Blackwood J, Kudenchuk PJ, Rea TD. Short ECG segments predict defibrillation outcome using quantitative waveform measures. Resuscitation 2016;109:16-20.

13. Indik JH, Conover Z, McGovern M, Silver AE, Spaite DW, Bobrow BJ, et al. Amplitudespectral area and chest compression release velocity independently predict hospital discharge and good neurological outcome in ventricular fibrillation outof-hospital cardiac arrest. Resuscitation 2015;92:122-8.

14. Indik JH, Conover Z, McGovern M, Silver AE, Spaite DW, Bobrow BJ, et al. Association of amplitude spectral area of the ventricular fibrillation waveform with survival of out-of-hospital ventricular fibrillation cardiac arrest. Journal of the American College of Cardiology 2014;64(13):1362-9.

15. Reynolds JC, Salcido DD, Menegazzi JJ. Correlation between coronary perfusion pressure and quantitative ECG waveform measures during resuscitation of prolonged ventricular fibrillation. Resuscitation 2012;83(12):1497-502.

16. Povoas HP, Bisera J. Electrocardiographic waveform analysis for predicting the success of defibrillation. Critical care medicine 2000;28(11 Suppl):N210-1.

17. Kleinman ME, Brennan EE, Goldberger ZD, Swor RA, Terry M, Bobrow BJ, et al. Part 5: Adult Basic Life Support and Cardiopulmonary Resuscitation Quality: 2015 American Heart Association Guidelines Update for Cardiopulmonary Resuscitation and Emergency Cardiovascular Care. Circulation 2015;132(18 Suppl 2):S414-35.

18. Dumas F, White L, Stubbs BA, Cariou A, Rea TD. Long-term prognosis following resuscitation from out of hospital cardiac arrest: role of percutaneous coronary intervention and therapeutic hypothermia. Journal of the American College of Cardiology 2012;60(1):21-7.

19. Foster A, Florea V, Fahrenbruch C, Blackwood J, Rea TD. Availability and Accuracy of EMS Information about Chronic Health and Medications in Cardiac Arrest. The western journal of emergency medicine 2017;18(5):864-869.

20. Charlson ME, Pompei P, Ales KL, MacKenzie CR. A new method of classifying prognostic comorbidity in longitudinal studies: development and validation. Journal of chronic diseases 1987;40(5):373-83.

21. Marn-Pernat A, Weil MH, Tang W, Pernat A, Bisera J. Optimizing timing of ventricular defibrillation. Critical care medicine 2001;29(12):2360-5.

22. Firoozabadi R, Nakagawa M, Helfenbein ED, Babaeizadeh S. Predicting defibrillation success in sudden cardiac arrest patients. Journal of electrocardiology 2013;46(6):473-9.

23. Coult J, Kwok H, Sherman L, Blackwood J, Kudenchuk PJ, Rea TD. Ventricular fibrillation waveform measures combined with prior shock outcome predict defibrillation success during cardiopulmonary resuscitation. Journal of electrocardiology 2018;51(1):99-106.

24. Lin LY, Lo MT, Ko PC, Lin C, Chiang WC, Liu YB, et al. Detrended fluctuation analysis predicts successful defibrillation for out-of-hospital ventricular fibrillation cardiac arrest. Resuscitation 2010;81(3):297-301.

25. Povoas HP, Weil MH, Tang W, Bisera J, Klouche K, Barbatsis A. Predicting the success of defibrillation by electrocardiographic analysis. Resuscitation 2002;53(1):7782.

26. Ajam K, Gold LS, Beck SS, Damon S, Phelps R, Rea TD. Reliability of the Cerebral Performance Category to classify neurological status among survivors of 
ventricular fibrillation arrest: a cohort study. Scandinavian journal of trauma, resuscitation and emergency medicine 2011;19:38. long-term prognosis following out-of-hospital cardiac arrest. Critical care medicine 2013;41(5):1252-7.

28. Lin DY, Fleming TR, De Gruttola V. Estimating the proportion of treatment effect explained by a surrogate marker. Statistics in medicine 1997;16(13):1515-27.

29. Neumar RW, Eigel B, Callaway CW, Estes NA, 3rd, Jollis JG, Kleinman ME, et al. American Heart Association Response to the 2015 Institute of Medicine Report on Strategies to Improve Cardiac Arrest Survival. Circulation 
Figure 1 : Flow chart of the study population

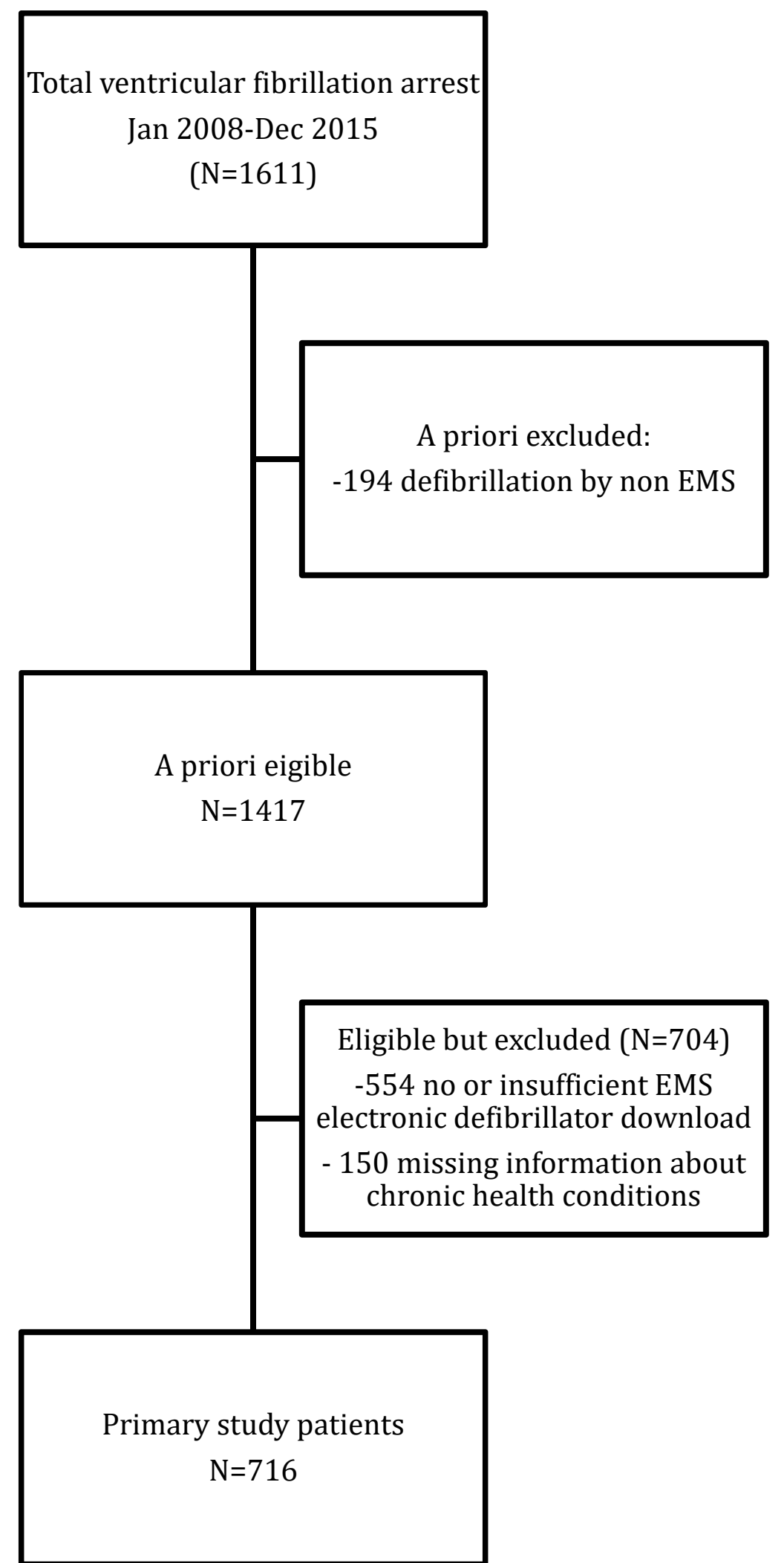


Table 1. Comparison between primary study patients and those eligible but excluded

\begin{tabular}{|c|c|c|c|}
\hline & $\begin{array}{c}\text { Primary } \\
\text { study cohort } \\
\mathrm{N}=716\end{array}$ & $\begin{array}{l}\text { Eligible } \\
\text { Excluded } \\
\mathrm{N}=704\end{array}$ & \\
\hline Age, years (SD) & $61.8(15.5)$ & $63.8(14.5)$ & 0.10 \\
\hline Male gender, n (\%) & $540(75)$ & $546(78)$ & 0.35 \\
\hline Public location, n (\%) & $174(24)$ & $249(35)$ & $<0.001$ \\
\hline Witnessed, n (\%) & $553(77)$ & $530(75)$ & 0.39 \\
\hline Bystander CPR, n (\%) & $515(72)$ & $442(63)$ & $<0.001$ \\
\hline EMS response interval $>5 \operatorname{min~} n(\%)$ & $350(50)$ & $338(52)$ & 0.44 \\
\hline Cardiac etiology, n (\%) & $663(93)$ & $634(90)$ & 0.09 \\
\hline $\mathrm{CCl}=0$ & $294(41)$ & $252(40)$ & 0.06 \\
\hline $\mathrm{CCl}=1$ & $156(22)$ & $125(20)$ & \\
\hline $\mathrm{CCl}=2$ & $140(20)$ & $119(19)$ & \\
\hline $\mathrm{CCl}=3$ & $74(10)$ & $57(9)$ & \\
\hline $\mathrm{CCl} \geq 4$ & $52(7)$ & $75(12)$ & \\
\hline AMSA (SD) & $7.31(4.0)$ & $7.52(3.8)$ & 0.28 \\
\hline Hospital survival, n (\%) & $324(45)$ & $316(45)$ & 0.89 \\
\hline
\end{tabular}


Table 2 : Utstein and AMSA covariates according to chronic health categories $(\mathrm{SD}=$ standard deviation, $\mathrm{CPR}=$ cardiopulmonary ressuscitation, $\mathrm{CCI}=$ Charlson comorbidity index, $\mathrm{p}$-value* for trend)

\begin{tabular}{lcccccc} 
& \multicolumn{7}{c}{ Charlson Comorbidity Index } & & \\
& $\mathrm{CCl}=\mathbf{0}$ & $\mathrm{CCl}=\mathbf{1}$ & $\mathrm{CCl}=\mathbf{2}$ & $\mathrm{CCl}=\mathbf{3}$ & $\mathrm{CCl} \geq \mathbf{4}$ & p-value* \\
& $\mathrm{N}=294$ & $\mathrm{~N}=156$ & $\mathrm{~N}=140$ & $\mathrm{~N}=74$ & $\mathrm{~N}=52$ & \\
Age years (SD) & $56.9(16.3)$ & $65.4(15.3)$ & $64.1(12.8)$ & $65.6(13)$ & $67.4(14.5)$ & $<0.001$ \\
Male gender, $\mathbf{n}(\%)$ & $222(76)$ & $121(78)$ & $102(73)$ & $55(74)$ & $40(77)$ & 0.83 \\
Public location, $\mathbf{n ( \% )}$ & $87(30)$ & $39(25)$ & $33(24)$ & $13(18)$ & $2(4)$ & $<0.001$ \\
Witnessed, $\mathbf{n}(\%)$ & $223(76)$ & $121(78)$ & $117(84)$ & $59(80)$ & $33(63)$ & 0.74 \\
Bystander CPR, $\mathbf{n}(\%)$ & $217(74)$ & $107(69)$ & $101(72)$ & $54(73)$ & $36(69)$ & 0.61 \\
EMS Response $>\mathbf{5}$ min, $\mathbf{n ( \% )}$ & $129(45)$ & $77(51)$ & $72(53)$ & $42(58)$ & $30(60)$ & 0.009 \\
Cardiac etiology, $\mathbf{n}(\%)$ & $269(92)$ & $146(94)$ & $134(96)$ & $68(92)$ & $46(88)$ & 0.99 \\
AMSA mean (SD) & $7.5(3.9)$ & $7.6(4.1)$ & $7.5(4.4)$ & $6.7(3.5)$ & $5.8(2.8)$ & 0.02
\end{tabular}


Table 3 : Utstein and chronic health conditions according to AMSA quartiles. ${ }^{*}$ dichotomized according to the median, SD= standard deviation, $\mathrm{CPR}=$ cardiopulmonary ressuscitation, $\mathrm{CCI}=$ Charlson comorbidity index)

\begin{tabular}{|c|c|c|c|c|c|}
\hline \multirow{2}{*}{ AMSA value } & \multicolumn{4}{|c|}{ AMSA Quartiles } & \multirow{3}{*}{ p-value } \\
\hline & $<4.20$ & $4.20-6.80$ & $6.80-9.60$ & $>9.60$ & \\
\hline & $\mathrm{N}=187$ & $\mathrm{~N}=180$ & $\mathrm{~N}=174$ & $\mathrm{~N}=175$ & \\
\hline Age, years (SD) & $63.8(15.2)$ & $62.9(15.4)$ & $61.9(16.2)$ & $58.5(14.9)$ & 0.008 \\
\hline Male gender, n(\%) & $149(80)$ & $138(77)$ & $124(71)$ & $129(74)$ & 0.10 \\
\hline Public location, n(\%) & $34(18)$ & 34 (19) & $48(28)$ & $58(33)$ & $<0.001$ \\
\hline Witnessed, n(\%) & $117(63)$ & $139(77)$ & $146(84)$ & $151(86)$ & $<0.001$ \\
\hline Bystander CPR, n(\%) & $117(63)$ & $127(71)$ & $131(75)$ & $140(80)$ & $<0.001$ \\
\hline EMS response $>5 \mathrm{~min}, \mathrm{n}(\%)$ & $85(24)$ & $86(25)$ & $90(26)$ & $89(25)$ & 0.46 \\
\hline Cardiac etiology, n(\%) & $171(91)$ & $165(92)$ & $161(93)$ & $166(95)$ & 0.21 \\
\hline \multirow[t]{5}{*}{$\mathrm{CCl}$} & $73(39)$ & $72(40)$ & $71(41)$ & $78(45)$ & 0.048 \\
\hline & $40(21)$ & $30(17)$ & $48(28)$ & $38(22)$ & \\
\hline & 33 (18) & $42(23)$ & $27(16)$ & $38(22)$ & \\
\hline & $23(12)$ & 19(11) & $19(11)$ & $13(7)$ & \\
\hline & $18(10)$ & $17(9)$ & $9(5)$ & $8(5)$ & \\
\hline
\end{tabular}


Table 4 : Logistic regression predicting survival at discharge ; (CPR=cardiopulmonary resuscitation ; CCI=Charlson comorbidity index $)$

\begin{tabular}{|c|c|c|c|c|c|c|c|c|c|}
\hline & \multirow{2}{*}{\multicolumn{3}{|c|}{ Unadjusted odds ratio of survival }} & \multicolumn{6}{|c|}{ Multivariable odds ratio of survival } \\
\hline & & & & \multicolumn{3}{|c|}{ Utstein-only adjusted } & \multicolumn{3}{|c|}{ Utstein and AMSA adjusted } \\
\hline & OR & $95 \% \mathrm{Cl}$ & p-value & OR & $95 \% \mathrm{Cl}$ & $\mathrm{p}$-value & OR & $95 \% \mathrm{Cl}$ & p-value \\
\hline Age & 0.97 & $(0.96-0.98)$ & $<0.001$ & 0.97 & $(0.96-0.98)$ & $<0.001$ & 0.97 & $(0.96-0.98)$ & $<0.001$ \\
\hline Male gender & 0.75 & $(0.54-1.06)$ & 0.10 & 0.69 & $(0.48-1.0)$ & 0.05 & 0.75 & $(0.50-1.11)$ & 0.15 \\
\hline Public location & 1.50 & $(1.06-2.11)$ & 0.02 & 1.04 & $(0.72-1.52)$ & 0.82 & 0.84 & $(0.56-1.27)$ & 0.41 \\
\hline Witnessed & 2.77 & $(1.89-4.07)$ & $<0.001$ & 2.56 & $(.70-3.86)$ & $<0.001$ & 1.99 & $(1.28-3.08)$ & 0.002 \\
\hline Bystander CPR & 1.22 & $(0.87-1.69)$ & 0.25 & 1.29 & $(0.89-1.85)$ & 0.18 & 0.97 & $(0.65-1.45)$ & 0.89 \\
\hline EMS Response time $<5$ min & 1.42 & $(1.05-1.92)$ & 0.02 & 1.53 & $(1.10-2.13)$ & 0.01 & 1.43 & $(1.01-2.04)$ & 0.045 \\
\hline Cardiac etiology & 2.45 & (1.30-4.59) & 0.005 & 3.27 & $(1.60-6.69)$ & 0.001 & 2.99 & $(1.39-6.45)$ & 0.005 \\
\hline $\mathrm{CCl}$ & 0.78 & $(0.70-0.89)$ & $<0.001$ & 0.82 & $(0.72-0.93)$ & 0.003 & 0.85 & $(0.74-0.98)$ & 0.025 \\
\hline AMSA & 1.31 & $(1.24-1.37)$ & $<0.001$ & --- & ---- & ---- & 1.27 & $(1.20-1.34)$ & $<0.001$ \\
\hline
\end{tabular}

